\title{
Evaluation of the Relationship between Covid-19 Pandemic and Research Productivity among Academic and Medical Staff Of Public Universities and Hospitals in Nasarawa State, Nigeria
}

\author{
${ }^{1}$ Maikudi Kwanza Allahnana, ${ }^{2}$ Godhas U. Ekpenyong \\ ${ }^{1} \mathrm{Ngozi}$ Violet Ofoegbunam, ${ }^{1}$ Isaac Jangson Kukwi \\ ${ }^{1}$ Department of Educational Foundations \\ Faculty of Education \\ Nasarawa State University \\ Keffi, Nigeria \\ ${ }^{2}$ Department of Economics \\ School of Secondary Education \\ Federal College of Education \\ Kontagora Niger State, Nigeria
}

Email: maikudiallahnana@gmail.com

\begin{abstract}
This study evaluates the relationship between COVID-19 pandemic and research productivity among academic and medical staff of public universities and hospitals in Nasarawa State, Nigeria. Correlational research design was used in this study. The researchers purposively used 2,543 respondents with 2 public universities and 2 public hospitals as the population of the study. Multistage random sampling technique was used to select 228 respondents with the same number of public universities and hospitals. The instrument used for data collection was COVID-19 Pandemic on Academic and Medical Staff Research Productivity (COVID-19 PAMSRP). The instrument was validated by the experts using e-face validity and the reliability index was 0.93 using Cronbach alpha method. Pearson Product Moment Correlation (r) was used for the analysis. The findings from the study revealed that, there was negative relationship between COVID-19 pandemic on academic and medical staff research productivity in Nasarawa State. By implication, COVID-19 pandemic affects both academic and medical staff. Based on the findings, it was recommended among others that both school and medical management should organize conferences, seminars and workshops for staff in such a way that it would improve the levels of their research productivity and services delivery for the safety of lives and Nigerian academics and medical staff should engage in reliable research that will lead to development and innovations for the improvement of education and health sectors.
\end{abstract}

Keywords: COVID-19 pandemic, research productivity. 


\section{INTRODUCTION}

Historically, research work from original knowledge or might reanalyze existing knowledge. Research in several scientific fields needs important funding for laboratories and instrumentation. In different disciplines, research might have solely basic library or web resources. Research will so take several forms and have totally different functions. The main target on discovery, interpretation and originality links the immense array of research themes, methodologies and orientations." Research is exploring for new knowledge. It's a scientific method to supply answers to unresolved issues. It's conjointly a scientific study of materials and sources so as to ascertain facts and reach new conclusions. Research productivity amongst academic and medical staff is one in every of the core price and functions of universities and health sector and it plays a basic role in national economic process and development. Suvendrini (2020) opined that the intense look for a Coronavirus Disease (COVID-19) pandemic immunogen has pushed medical examiners to the highest of cooperative medical researchers comes between Japanese universities, drug corporations and therefore the government in Japan.

This has conjointly joined to the availability of COVID-19 immunogen by medical researchers. However, universities and health sector still face low and skew research productivity. The COVID-19 pandemic, that causes the acute respiratory disorder was 1st detected in metropolis, China in December 2019. This primary irruption has since unfolded to the majority the countries worldwide. The globe health organization (WHO) declared a worldwide pandemic on eleventh March, 2020. The quantity of individuals affected is increasing speedily. As at $5^{\text {th }}$ August, 2020 research had shown that 986,212 infected cases, 21,193 Deaths cases, and 659,280 discharge cases globally. Also in Nigeria, there were 44,433 confirmed cases, 910 deaths and 31,851 recoveries (NCDC, 2020). As a results of this, several academics and medical staff were affected economically, socially, psychologically, medically, religiously, etc. Hence, they might not attend conferences, seminars and workshops.

COVID-19 poses new institutional responsibilities and challenges, together with the necessity to make sure continuity of current academic and medical research, increase COVID-19-related research, guarantee safety of lives, enforce social distancing measures, guarantee continued the education of scholars, limit non-essential, non-COVID-19 research activities, and maintain needed animal care resources (WHO, 2020). Medical researchers adopted multiple methodologies and approaches to address onsite laboratory instrumentality restrictions and shutdowns. Academic and medical researchers have equilibrium and maintained crucial research activities, continued to submit publications, balanced work and family responsibilities, initiated or collaborated on COVID-19 - connected research, ensured restricted onsite laboratory staffing, engaged in remote research opportunities, maintained regular and frequent communication with trainees and coworkers, and continued to arrange and write research grants to tackle with the challenges of COVID-19 pandemic (Jeetendra et al., 2020).

Research is associate degree application of the creation of latest knowledge and also the use of existing knowledge during a new approach and inventive approach therefore on generate new ideas, methodologies and understanding to resolve issues no matter the surroundings (ARC, 2010) as cited in Sujit, 2014). Research includes activities that meet the immediate wants of research shoppers, operating to get and improve knowledge and undertakings that bring forth improvement in customary of living with existing information. Research activities are the 
processes, cash and energy invested with in analysis, and will embrace reading concerning research, acquisition of competitive research grants, acting on a look project, reviewing research proposals, discussing research with colleagues, and networking with national and international researchers.

Sujit (2014) opined that research productivity is a lot of operate of educational and medical staff motivation than of resource support. Research performance is typically used interchangeably with research productivity. Sujit (2014) reported that analysis productivity involves research publications in journals and conference proceedings, books, chapter writing, gathering and research original proof, operating with postgraduate students on dissertations and sophistication comes, securing research grants, concluding editorial duties, obtaining patents and licenses, writing monographs, developing experimental styles, manufacturing the work of an inventive of an explicit nature, and interesting publicly debates and commentaries. inexperienced and Sujit (2014) declared that in university education system, analysis productivity for the school members is growing worldwide and research scholarship within the putative peer-reviewed publication seems essential for fulfillment by educational workers in the slightest degree universities for the event of educational activities, information and education at massive.

Sujit (2014) discovered that within the university, research productivity relies on the amount and quality of erudite articles printed by researchers, as schools and departments area unit assessed and evaluated supported their publication count. the most perform of educational and medical workers in Nigerian universities and hospitals is to develop human resource through teaching, learning, safety of lives and research. This perform is administered at completely different levels of educational and health atmosphere for the development of each the education and health sectors. However, for the aim of this study, research is seen as a scientific method for search of recent information in academic and medical atmosphere for the aim of discovering new concepts or elucidating on existing ones and usually contributory to knowledge for the protection of lives and properties for human and economy development. Although, research is administered at completely different levels in several institutions, those conducted in academic and health establishments, and maybe those by the academic and medical staff areas unit the foremost necessary to the society and nation at massive. Academic and medical staff so, occupy a central position in research activities and productivity within the nation's academic establishments. The term academic and medical staff has been diversely outlined. Romanus (2013) outlined academic and medical staff as people used in academic and medical atmosphere whose responsibilities area unit to show, give health care services and conduct valid and reliable research resulting in improvement within the society and therefore the economy of the state at massive.

Research productivity has been outlined because of the relationship between the outputs generated by a system and therefore the inputs provided to form those outputs. It conjointly includes the term 'efficiency' and additional significantly 'effectiveness' that measures the full output or results of performance for the accomplishment (Turnage, 1990 as cited in Lertputtarak, 2008). Print and Hattie (1997) as cited in Lertputtarak (2008) asserted that research productivity is that the totality of research performed by academic staff in the universities and connected contents among a given period of time and analysis potency has been outlined because the productivity of research per unit of input resource supported the profession. 
COVID-19 additionally has caused a great deal of downside for each academic and medical staff in terms of research productivity wherever they notice it tough to attend traditional or physical conferences, seminars, workshops \{and the and therefore the and additionally the price of publications and transportation also increased. Several academic and medical staff lost their lives because of COVID-19 pandemic and it affected their levels of research productivity furthermore because the economy of the state. Academic and medical staff research productivity may be a major indicator and determinant of academic and medical staff productivity within the university education system. For academic staff, it's a very important proof in class management choices on research staff workers appointments, career development, promotions, university assessment, evaluation, ranking and recognition each domestically, national and internationally. Whereas for medical staff it's vital for the supply of recent medicine, solutions to new diseases, safety of lives and therefore the improvement of health sector usually. In sight of this, academic and medical staff has to conduct valid and reliable research frequently so as to fulfill the desired publication productivity and bring home the bacon property development goals (SDGs) for his or her career advancement and health care service. Despite the large quantity of cash spent by centralized of Federal Republic of Nigeria in academic and medical researches, it's not sure whether or not most good thing about these resources springs by the users, particularly the academic and medical staff with regards to their research productivity. The aim of this study is to judge the connection between COVID-19 pandemic and research productivity among academic and medical staff of public universities and hospitals in Nasarawa State, Federal Republic of Nigeria in respect to conferences, workshops, seminars and book publications.

Boice (1987) in Lertputtarak (2008) pointed out that a replacement pedagogue World Health Organization might notice only 1 hour per weekday to figure on their analysis, typically managed to submit regarding one.5 manuscripts each year, that is then in line with the expectations for a pay rise and better tenure standing and any school members World Health Organization adopt a program of transient daily periods for analysis comes generally expertise less stress in managing their time and their lives.

Suwanwala (1991) in Lertputtarak (2008) pointed out that several lecturers failed to understand the importance of conducting research, and plenty of them lacked the information, skills, expertise and resources to try and do research. Juthawattanathorn (1994) in Lertputtarak (2008) investigated the issues related to national research fund allocation and located that the bulk of research funds that were awarded by the government weren't decent for the research undertaken, and also the systems for fund allocation weren't versatile. Consequently, there have been several universities that received lean funds for research development, and that they were then unable to change their proposals to suit the on the market budget and Mahidol University discovered that institutional policy and lean research funds were important obstacles. This was additionally to the additional general observation that academic members at this establishment conjointly seemed to lack data and confidence to try to research, associated there was conjointly an unhelpful lack of criteria to live research quality.

Paul et al (2013) in Sujit (2014) conducted AN intensive study within the USA on the role of mentoring on the general analysis productivity of an physiatrics college and located out that handiness of applied math computing facilitate, correlative completely with analysis productivity for all colleges. Abid, et al. (2020) confirmed that COVID-19 pandemic has affected 
day to day life activities and is fastness down the world economy movement. This pandemic has affected thousands of properties and lives WHO area unit either sick or area unit being killed because of the unfold of this sickness. They additionally thought of fever, cold, cough, bone pain and respiratory issues as a number of the foremost common symptoms of this COVID-19 pandemic wherever it speedily affected way of life, businesses, routine activities, noncontinuous the world trade and movements.

Zainab (2001) rumored that there was a major distinction between publication productivity of academic scientists which of engineers. Tower et al (2005) noted that there was terribly low analysis output in accounting and also the few research activities during this discipline were found among lower level academic staff in accounting department. The study conjointly thought-about the subsequent because the factors influencing publication output via: rank, ability to secure research grants, qualification and gender. The similarity between the 2 studies lies in making an attempt to search out however rank influences the publication output of academic staff. However, Tower e tal (2015) studied solely academic staff of accounting discipline whereas the current study investigated all academic and medical staff no matter their disciplines.

Abide et al (2020) reportable that COVID-19 pandemic has affected day to day life activities and is deceleration down the worldwide economy movement. This pandemic has affected thousands of properties and lives World Health Organization are either sick or are being killed thanks to the unfold of this illness. They conjointly thought of fever, cold, cough, bone pain and respiratory issues as a number of the foremost common symptoms of this COVID-19 pandemic wherever it apace affected standard of living, businesses, routing activities, noncontinuous the worldwide trade and movements.

Bassey et al (2007) revealed that male academic staff in Nigerian universities engage in more research activities that their female counterparts and that married academic staff turn out more publications than their unmarried counterparts. The study also revealed that academic staff area of specialization significantly influenced their publication output. Okafor (2010) found out that there was a significant difference in the publication output between the academic staff in the faculties of sciences from those in the engineering faculties. It further revealed that within the science faculty, academic staff in zoology department published more than those in computer science. It also revealed that within the faculty of engineering, academic staff in petroleum/chemical engineering turned out more publication output than others. 


\section{MATERIAL AND METHOD}

\section{Research Design}

For the purpose of this research, correlational research design was used to conduct this research study.

\section{Population}

The researchers purposively used 2,543 respondents with 2 public universities (Nasarawa State University, Keffi and Federal University, Lafia) and 2 public hospitals (Federal Medical Centre Keffi and Specialist hospital, Lafia) as the population of the study. These establishments were chosen because they are located an area of high research productivity. Multistage random sampling technique was used to select 228 respondents with the same number of public universities and public hospitals that reflected as population.

\section{Method of Data Collection}

COVID-19 Pandemic on Academic and Medical Staff Research Productivity (COVID-19 PAMSRP) questionnaire was used as an instrument for data collection in this study. The instrument contained 40 questions constructed by the researchers in such a way that, the respondents answered Yes or No. The instrument was validated by the experts and the reliability index obtained was 0.93 using Cronbach's alpha method.

\section{Method of Data Analysis}

Pearson Product Moment Correlation (r) was used for data analysis. The variables tested in the study are: COVID-19, conferences, workshops, seminars, articles and book publications.

\section{Results}

\section{Table 1}

\begin{tabular}{|c|c|c|c|c|c|c|}
\hline Variables & $\mathbf{N}$ & Means & STD & $\mathbf{R}$ & df & Sig (P) \\
\hline$\overline{\text { COVID-19 }}$ & 288 & 57.345 & 3.143 & 0.765 & 286 & 0.001 \\
\hline Conferences & & 42.243 & 2.034 & & & \\
\hline
\end{tabular}

Table 1 shows that significant relationship exists between COVID-19 pandemic and conference attended among academic and medical staff of public universities and hospitals in Nasarawa state, Nigeria. This is because the calculated significant (p) value of 0.001 is less than 0.05 alpha level of significance at a correlation index $r$ value of 0.756 . This implies that the higher the level of COVID-19 pandemic, the greater conference attended among academic and medical staff and vice versa. 
Table 2

COVID-19 Pandemic and Workshops Attended among Academic and Medical Staff

\begin{tabular}{lcccccc}
\hline Variables & $\mathbf{N}$ & Means & STD & R & df & Sig (P) \\
\hline COVID-19 & & & & & \\
& 288 & 66.434 & 2.675 & -0.634 & 286 & 0.002 \\
Workshops & & 42.653 & 1.341 & & & \\
\hline
\end{tabular}

Table 2 shows that significant relationship exists between COVID-19 pandemic and workshop attended among academic and medical staff of public universities and hospitals in Nasarawa state, Nigeria. This is because the calculated significant (p) value of 0.002 is less than 0.05 alpha level of significance at a correlation index $r$ value of -0.634 . This implies that the higher the level of COVID-19 pandemic, the less the textbook published among academic and medical staff and verse versa.

Table 3

COVID-19 Pandemic and Seminars Attended among Academic and Medical Staff

\begin{tabular}{lcccccc}
\hline Variables & $\mathbf{N}$ & Means & STD & R & df & Sig (P) \\
\hline COVID-19 & 288 & 67.784 & 4.675 & & & \\
& & & & 0.765 & 286 & 0.000 \\
Seminars & & 56.842 & 2.084 & & & \\
\hline
\end{tabular}

Table 3 shows that significant relationship exists between COVID-19 pandemic and seminars attended among academic and medical staff of public universities and hospitals in Nasarawa state, Nigeria. This is because the calculated significant $(p)$ value of 0.000 is less than 0.05 alpha level of significance at a correlation index $r$ value of 0.765 . This implies that the higher the level of COVID-19 pandemic, the greater the seminars attended among academic and medical staff in order to proffered solution to COVID-19 pandemic.

Table 4

COVID-19 Pandemic and Journal Publication among Academic and Medical Staff

\begin{tabular}{lcccccc}
\hline Variables & $\mathbf{N}$ & Means & STD & R & df & Sig (P) \\
\hline COVID-19 & 288 & 69.793 & 4.391 & 0.762 & 286 & -0.001 \\
Journals & & & & & & \\
\hline
\end{tabular}

Table 4 shows that negative significant relationship exists between COVID-19 pandemic and journal publications among academic and medical staff of public universities and hospitals in Nasarawa state, Nigeria. This is because the calculated significant (p) value of -0.001 is less than 0.05 alpha level of significance at a correlation index $r$ value of 0.762 . This implies that the 
higher the level of COVID-19 pandemic, the less the journal publications among academic and medical staff and verse versa.

Table 5

COVID-19 Pandemic and Textbook Publication among Academic and Medical Staff

\begin{tabular}{lllllll}
\hline Variables & $\underline{\mathbf{N}}$ & $\underline{\text { Means }}$ & $\underline{\mathbf{S . D}}$ & $\underline{\mathbf{R}}$ & $\underline{\text { df }}$ & Sig (P) \\
\hline COVID-19 & 288 & 45.674 & 3.574 & & & \\
& & & & 0.783 & 386 & 0.002 \\
Textbooks Publication & 2288 & 52.466 & 4.165 & 0.765 & 286 & 0.003
\end{tabular}

Table 4 shows that significant relationship exists between COVID-19 pandemic and textbook publication among academic and medical staff of public universities and hospitals in Nasarawa state, Nigeria. This is because the calculated significant $(\mathrm{p})$ value of 0.002 is less than 0.05 alpha level of significance at a correlation index $r$ value of 0.783 . This implies that the higher the level of COVID-19 pandemic, the less the textbook published among academic and medical staff and verse versa.

\section{DISCUSSION}

First finding from the study shows that significant relationship exists between COVID-19 pandemic and conferences attended among academic and medical staff of public universities and hospitals in Nasarawa state, Nigeria. This is because the calculated significant (p) value of 0.001 is less than 0.05 alpha level of significance at a correlation index $r$ value of 0.692 . Therefore, the null hypothesis which states that there is no significant relationship between COVID-19 pandemic and conference attended among academic and medical staff of public universities and hospitals in Nasarawa state, Nigeria is hereby rejected. This goes in line with the research work of Suwanwala (1991) in Lertputtarak (2008) who found that many lecturers did not realize the important of conducting research, and many of them lacked the knowledge, skills, experience and resources to do research. Abid, e tal (2020) confirmed that COVID-19 pandemic has affected day to day life activities and is slowing down the global economy movement. This pandemic has affected thousands of properties and lives who are either sick or are being killed due to the spread of this disease. They also considered fever, cold, cough, bone pain and breathing problems as some of the most common symptoms of this COVID-19 pandemic where it rapidly affected daily life, businesses, routine activities, disrupted the global trade and movements.

Second finding from the study shows that significant relationship does not exists between COVID-19 pandemic and workshops attended among academic and medical staff of public universities and hospitals in Nasarawa state, Nigeria. This implies that the higher the level of COVID-19 pandemic, the greater workshops among academic and medical staff and vice versa. This finding corroborate with the work of Juthawattanathorn (1994) in Lertputtarak (2008) who found that the majority of research funds which were awarded by the government were not sufficient for the research undertaken, and furthermore that the systems for fund allocation were not flexible. 
Third finding from the study shows that significant relationship exists between COVID-19 pandemic and seminars attended among academic and medical staff of public universities and hospitals in Nasarawa state, Nigeria. This implies that the higher the level of COVID-19 pandemic, the greater the seminars attended among academic and medical staff in order to proffered solution to COVID-19pandemic.Therefore, the null hypothesis which states that there is no significant relationship between COVID-19 pandemic and seminars attended among academic and medical staff of public universities and hospitals in Nasarawa state, Nigeria is hereby rejected. This finding supports the research work of Okafor (2010) who found out that there was a significant difference in the publication output between the academic staff in the faculties of sciences from those in the engineering faculties and it also further revealed that within the science faculty, academic staff in zoology department published articles more than those in computer science.

Fourth finding from the study shows that negative significant relationship exists between COVID-19 pandemic and journal publications among academic and medical staff of public universities and hospitals in Nasarawa state, Nigeria. This finding agreed with the work of Tower et al (2005) who found out that there is very low research output in accounting and the few research activities in this discipline were found among lower level academic staff in accounting department.

Lastly, fifth finding from the study shows that significant relationship exists between COVID19 pandemic and textbook publication among academic and medical staff of public universities and hospitals in Nasarawa state, Nigeria. This finding agreed with Lertputtarak (2008) who found out that institutional policy and insufficient research funds were significant obstacles. All the studies that were review are related to the present study in terms of the variables and findings. But none of the study was conducted exactly on the evaluation of the relationship between COVID-19 pandemic and research productivity among academic and medical staff of public universities and hospitals in Nasarawa state, Nigeria. This served as the knowledge gap of the present study.

\section{CONCLUSION}

The findings from the study revealed that significant relationship exists between COVID-19 pandemic and research productivity among academic and medical staff of public universities and hospitals in Nasarawa state, Nigeria. COVID-19 has caused a lot of problem for both academic and medical staff in terms of research productivity where they find it difficult to attend traditional or physical conferences, seminars, workshops and the cost of publications has increased. It also affected people physically, psychologically, socially, medically, economically, publicly, etc. Many academic and medical researchers lost their lives because of COVID-19 pandemic and it also affected the levels of research productivity and the economy of the nation. Consequently, government at all levels of universities and hospital management should try as much possible to ensure all necessary research resources that enhance high level of research productivity by academic and medical staff are available, utilize, adequately and use effectively for the development of both education and health sectors. This will make the academic and medical staff to rise up and to provides solution to the challenges of publication output and ensure the realization of the overall objectives of education and health care services and the development of the nation economy generally. 
Based on the findings of this study, the following recommendations were made:

1. Both the university and health management should assist financially and organize conferences for academic and medical staff in this COVID-19 pandemic period.

2. Federal Government of Nigeria should re-train and re-organize workshops on COVID-19 pandemic for academic and medical staff of public universities and hospitals and they should be supported financially.

3. University and health management should organize seminars on COVID-19 pandemic period for both academic and medical staff and they should also be motivated financially.

4. University and health management should motivate both academic and medical staff on journal publication by financing the publication in this COVID-19 pandemic period.

5. Both the university and health management should make textbook publications free for both academic and medical staff in this COVID-19 pandemic period.

\section{Acknowledgement}

We would like to thank the two reviewers for their deep and constructive comments.

\section{REFERENCES}

Abid, H., Raju, V. \& Mohd, J. (2020). Effects of COVID-19 pandemic in daily life. Current Medicine Research and Practice.file:// / :/Users/user/AppData/Local/Temp/Effectso fCOVID-19pandemicindailylife.pdf.

Australian Research Council (2010). Excellence in Research for Australia, Australian Government, Australian Research Council, Canberra.

Bassey, U.,Akuegwu, B. Udida, L. \& Udey. F. U. (2007). Academic Staff Research Productivity: A Study of Universities in South-South Zone of Nigeria. Educational Research and Review 2 (5): 103-108

Bishr, O.M., Jeetendra, E., David, S. K., Prabhas V. M., Reynold, A. P. J.R. \& Kathleen, W. S.(2020). The COVID-19 pandemic and research shutdown: staying safe and productive. The Journal of Clinical Investigation.130(6):2745-2748 Retrieved 19/8/2020. https://doi.org/10.1172/JCI138646

Boice, R. (1987). Habits of research productivity', Accounting Education News, Late Fall, p. 7.

Juthawattanathorn, M. (1994). Thailand Research and Development, National Research Council of Thailand, Thailand.

Lertputtarak, S. (2008). An Investigation of Factors Related to Research Productivity in a Public University in Thailand: A Case Study. A dissertation submitted in partial fulfilment of the requirements for the Degree of Doctor of Education, School of Education, Faculty of Arts, Education and Human Development,Victoria University, Melbourne, Australia. Retrieved on 2/8/2020 from http:/ / wallaby.vu.edu.au/adtVVUT/uploads/approved/adt UT20080 711.120505/public/01front.pdf

Nigeria Centre for Disease Control: retrieved from www.covid19.ncdc.gov.ng| www.ncdc.gov.ng on 15/8/2020.

Okafor, V.N. (2010). Analysis of research output of academics in science and engineering faculties in southern Nigeria. 
Retrieved 8/9/2020 from http://www.unn.edu.ng/library/images/analysis of research output of academics in science and engineering faculties in southern Nigeria-1.

Paul, S., Karuppiah,V., Singh, P.K. \& Burma, R. R. ( 2013). Research productivity of agricultural scientists: Evidences from high performing and low performing institutes, Indian Journal of Agricultural Sciences.

Popoola, S.O. (2008). The use of information resources and services and its effect on the research output of social scientists in Nigerian universities. Library Philosophy and Practice. Retrieved 6/9/2020 http://www.webpages.uidaho.edu/ mbolin/popoola.htm.

Print, M. \& Hattie, J. (1997). Measuring quality in universities: an approach to weighting research activity', Higher Education, vol. 33, pp. 453-469.

Romanus, O. A. (2013). Libraryre sources utilization and publication output of academic staff of polytechnics in south-east and south-south Nigeria. A thesis submitted to the department of library and information science in fulfilment of the requirements for the award of Doctor of Philosophy (Ph.D) in library and information science University in Nigeria.

Sujit, K. B. (2014). A Model Using ICT Adoption and Training to Improve the Research Productivity of Academics. Submitted in fulfilment of the requirement of the Doctor of Technology degree in Information Technology in the Department of Information Technology, Faculty of Accounting and Informatics, Durban University of Technology, Durban, South Africa.

Suvendrini, K. (2020).Vaccine research deepens university-industry collaboration. University world news. The global window on higher education.

Suwanwala, J. (1991) The road of University, Chulalongkorn University Press, Bangkok, Thailand.

Tower, G., Desai, R., Carson, B. \& Cheng, S. (2005). Better understanding of research performance. Asian Review of Accounting, 13 (2), 51 - 67.

Turnage, J. (1990). 'The challenge of the new workplace technology for psychology', American Psychologist, vol. 45, no. 3, pp. 171-178.

WHO Coronavirus Disease (COVID-19) Dashboard (source for global updates). Retrieved from https://covid-19.who.in on 5th August, 2020.

Zainab, A.N. (2001). Exploring the factors related to academic publication productivity among selected Malaysian academics. Unpublished PhD Thesis, Loughborough University. 


\section{APPENDIX A \\ QUESTIONNAIRE ON COVID-19 PANDEMIC FOR ACADEMIC \& MEDICAL STAFF RESEARCH PRODUCTIVITY (COVID-19 PAMSRP)}

Our names are Dr. Maikudi Kwanza Allahnana, Godhas U. Ekpenyong, Ngozi Violet Ofoegbunam and Prof. Isaac J. Kukwi of Nasarawa State University Keffi, Nigeria conducting a research titled: Evaluation of the relationship between COVID-19 pandemic and research productivity among academic and medical staff of public universities and hospitals in Nasarawa State, Nigeria. The research will provide information that will assist in the design, development and formulation of universities and health sector research productivity that should be emphasized in order to further encourage academic and medical staff to increase the levels of their research productivity. We will appreciate your assistance in this important research study. It is anticipated that this research and your responses will provide new perspectives on the Evaluation of the relationship between COVID-19 pandemic and research productivity among academic and medical staff of public universities and hospitals in Nasarawa State, Nigeria because the research method employed focused on quantitative understanding drawn from key informants in the area. Therefore, please answer as fully and truthfully as possible for the contribution to scholarly knowledge.

Please tick your answer with $(\sqrt{ })$

Profession: Academic Staff ( ) Medical Staff ( )

\begin{tabular}{|c|c|c|c|}
\hline $\mathbf{S} / \mathbf{N}$ & QUESTIONS & YES & NO \\
\hline 1 & Did you contribute to any textbooks in this COVI-19 pandemic period? & & \\
\hline 2 & Did you contribute to any manual in this COVID-19 pandemic period? & & \\
\hline 3 & Did you contribute to any book chapters in this COVI-19 pandemic period? & & \\
\hline 4 & Did you review any book in this COVI-19 pandemic period? & & \\
\hline 5 & Did you contribute to any Article in this COVI-19 pandemic period? & & \\
\hline 6 & Did you attend and present any paper at conference in this COVI-19 pandemic? & & \\
\hline 7 & Did you attend any seminars in this COVI-19 pandemic period? & & \\
\hline 8 & Did you attend any workshops in this COVI-19 pandemic period? & & \\
\hline 9 & Did you contribute to any Bulletin in this COVI-19 pandemic period? & & \\
\hline 10 & Did you contribute to any Newsletters in this COVID-19 pandemic period? & & \\
\hline 11 & Did you contribute to any Government Documents in this COVI-19 pandemic period? & & \\
\hline 12 & Did you contribute to any abstracts and indexes in this COVI-19 pandemic period? & & \\
\hline 13 & Did you contribute to any conference proceedings in this COVI-19 pandemic period? & & \\
\hline 14 & Did you contribute to any Newspapers in this COVI-19 pandemic period? & & \\
\hline 15 & Did you contribute to any Magazines in this COVID-19 pandemic period? & & \\
\hline 16 & Did you contribute to any monographs in this COVID-19 pandemic period? & & \\
\hline 17 & Did you contribute to any Journals in this COVI-19 pandemic period? & & \\
\hline 18 & Did COV-19 pandemic affect your research productivity? & & \\
\hline
\end{tabular}




\begin{tabular}{|c|c|}
\hline 19 & $\begin{array}{l}\text { Did your school/ hospital organized any workshop/ seminar on COVID-19 preventing } \\
\text { measures? }\end{array}$ \\
\hline 20 & What is the name and nature of textbooks you contributed in this COVI-19 pandemic period? \\
\hline 21 & What is the nature and name of manual you contributed in this COVID-19 pandemic period? \\
\hline 22 & $\begin{array}{l}\text { What is the nature and name of the book chapters you contributed in this COVI-19 pandemic } \\
\text { period? }\end{array}$ \\
\hline 23 & What is the name and nature book you reviewed in this COVI-19 pandemic period? \\
\hline 24 & What is the name and nature of the Article you contributed in this COVI-19 pandemic period? \\
\hline 25 & $\begin{array}{l}\text { What is name and nature of the conference you attended and presented a paper in this COVI-19 } \\
\text { pandemic? }\end{array}$ \\
\hline 26 & What is the name and nature of the seminars you attended in this COVI-19 pandemic period? \\
\hline 27 & What is the name and nature of the workshops you attended in this COVI-19 pandemic period? \\
\hline 28 & What is the name and nature of the Bulletin you contributed in this COVI-19 pandemic period? \\
\hline 29 & $\begin{array}{l}\text { What is the name and nature of the Newsletters you contributed in this COVID-19 pandemic } \\
\text { period? }\end{array}$ \\
\hline 30 & $\begin{array}{l}\text { What is the name and nature of the Government Documents you contributed in this COVI-19 } \\
\text { pandemic period? }\end{array}$ \\
\hline 31 & $\begin{array}{l}\text { What is the name and nature of the abstracts and indexes you contributed in this COVI-19 } \\
\text { pandemic period? }\end{array}$ \\
\hline 32 & $\begin{array}{l}\text { What is the name and nature of the conference proceedings you contributed in this COVI-19 } \\
\text { pandemic period? }\end{array}$ \\
\hline 33 & $\begin{array}{l}\text { What is the name and nature of the Newspapers you contributed in this COVI-19 pandemic } \\
\text { period? }\end{array}$ \\
\hline 34 & $\begin{array}{l}\text { What is the name and nature of the Magazines you contributed in this COVID-19 pandemic } \\
\text { period? }\end{array}$ \\
\hline 35 & $\begin{array}{l}\text { What is the name and nature of the monographs you contributed in this COVID-19 pandemic } \\
\text { period? }\end{array}$ \\
\hline 36 & What is the name and nature of the Journals you contributed in this COVI-19 pandemic period? \\
\hline 37 & How did COV-19 pandemic affect your research productivity? \\
\hline 38 & Do you want government to come intervene on your research productivity? \\
\hline 39 & Recommend how you want government to intervened in your research productivity \\
\hline 40 & Suggest a key way for improvement in your research productivity \\
\hline
\end{tabular}

